\title{
LITERATURE REVIEW : PENERAPAN COUNTER PRESSURE UNTUK MENGURANGI NYERI PERSALINAN KALA I
}

\author{
Erni Juniartati ${ }^{1)}$ Melyana Nurul Widyawati ${ }^{2)}$ \\ E-mail address: erni78.juniartati@gmail.com
}

\begin{abstract}
The Pain is a natural process of labor, but if not handled properly, it will cause another problem, namely increasing anxiety in the labour process. So that the production of adrenaline hormone increases and results in vasoconstriction that causes maternal blood flow to the fetus to fall. During this time, pain management using drugs but many drugs except expensive, contains a side effect too. So, non pharmacological methods are more recommended because they safe for pregnant women. One of the non pharmacological recommended is Counter Pressure.

Article searching conducted in some databases: Google Scholar, Proquest and Science Direct. Keyword used were "Counter Pressure", "pain", Labour"and finally got 10 articles matched (4 international articles and 6 national articles). Counter Pressure could be categorized as a safe and effective intervention to reduce labor pain at first phase. Using Counter Pressure will close the pain stimulus that will be delivered to the spinal cord and brain. Endorphin compounds will be activated at Counter Pressure so that the transmission of pain messages can be inhibited which can cause significant decrease in pain sensation. Counter Pressure could reduce labour pain at first phase.

Keywords: Counter Pressure; Pain; Labour

${ }^{1)}$ Student Of Midwifery Applied Masters Study Program, Poltekkes Kemenkes Semarang

${ }^{2)}$ Lecturer Of Midwifery Applied Masters Study Program, Poltekkes Kemenkes Semarang
\end{abstract}

\section{Pendahuluan}

Persalinan adalahsuatu proses alamiah yang akan dihadapi oleh setiap ibu hamil, di mana terjadi pengeluaran hasil konsepsi berupa bayi dan plasenta dari rahim ibu. Pada saat terjadi kontraksi, maka mulut rahim akan melebarsehingga mendorong bayi keluar.Tulang pubis menerima tekanan kuat dari rahim, hal inilah yang menyebabkannyeri pada persalinan.(Detiana, 2010)

Kontraksi rahim akan menimbulkan rasa nyeri bagi ibu yang mengalami proses persalinan. Sensasi nyeri yang dirasakan ibu hamil akan berbeda

kurangnya pengetahuan pada ibu akan proses yang terjadi di saat kadarnya, ada yang benar benar merasakan sakit yang luar biasa, namun juga banyak merasa nyeri yang tidak terlalu lama. Tentunya hal ini banyak faktor penyebabnya. dimulai dari pengalaman melahirkan, ukuran dan berat bayi, dukungan suami dan keluarga, pengalaman, teknik melahirkan, bahkan dari penolong medis mulai dari dokter atau bidan itu sendiri.(Okta Dwienda, 2015)

Nyeri adalah hal yang lumrah dalam persalinan. Tetapi apabila tidak diatasi dengan baik akan menimbulkan masalah lain yaitu meningkatnya kecemasan atau rasa khawatir karena menghadapi persalinan, sehingga produksi hormon adrenalin meningkat 
dan mengakibatkan vasokonstriksi yang menyebabkan aliran darah ibu ke janin menurun. (Bobak IM, 2012)

Pelepasan hormon seperti katekolamin dan steroidyang berlebihan menyebabkan terjadinya ketegangan otot polos dan vasokonstriksi pembuluh darah. Sehingga dapat mengakibatkan penurunan kontraksi uterus, penurunan sirkulasi uteroplasenta, pengurangan aliran darah dan oksigen ke uterus, serta timbulnya iskemia uterus yang membuat impuls nyeri bertambah banyak (Azizah, Widyawati, \& Anggraini, 2013)

Pada saat kala I persalinan, rasa nyeri akan muncul disebabkan karena adanya kontraksi otot-otot uterus, hipoksia dari otot-otot yang mengalami kontraksi, peregangan serviks, iskemia korpus uteri, dan peregangan segmen bawah rahim. Lewat segmen saraf spinalis T11-12 dan saraf - saraf asesori torakal bawah serta saraf simpatik lumbal atasreseptor nyeri akan ditransmisikan. Rangsangan nyeri ini berjalan mulai dari perifer melalui medullla spinalis, batang otak, thalamus dan kortek serebri. Ketika persalinan mengalami kemajuan, intensitas setiap kontraksi meningkat, menghasilkan intensitas nyeri yang lebih besar,(Reeder S.J. Martin L.L, 2014)

Pemberi asuhan pelayanan harus memperhatikan kenyamanan ibu yang akan melahirkan, salah satunya adalah penanganan nyeri persalinan. Penolong persalinan seringkali melupakan untuk menerapkan teknik pengontrolan nyeri, hal ini akan menyebabkan ibu bersalin memiliki pengalaman persalinan yang buruk, mengalami trauma persalinan yang dapat menyebabkan postpartum blues, maka sangat penting untuk penolong persalinan memenuhi kebutuhan ibu akan rasa aman dan nyaman.(Setyowati, 2018)

Upaya untuk menurunkan nyeri pada persalinan dapat dilakukan baik secara farmakologi maupun non farmakologi. Manajemen nyeri secara farmakologi lebih efektif dibanding dengan metode non farmakologi, namun metode farmakologi lebih mahal, dan berpotensi mempunyai efek samping yang kurang baik. Sedangkan metode non farmakologi lebih murah, simpel, efektif dan tanpa efek yang merugikan dan dapat meningkatkan kepuasan selama persalinan, karena ibu dapat mengontrol perasaannya dan kekuatannya, (Danuatmaja, 2014)

Beberapa contoh metode non farmakologi yang dapat digunakan untuk menurunkan nyeri antara lain teknik relaksasi, imajinasi, pergerakan dan perubahan posisi, umpan balik biologis, abdominal lifting, effleurage, hidroterapi, hipnoterapi, homeopati, terapi counter pressure, terapi musik, akupresur, akupunktur, dan aromaterapi. (Aprilia, 2011)

Massage counter pressure adalah pijatan yang dilakukan dengan memberikan tekanan yang terusmenerus pada tulang sakrum pasien dengan pangkal atau kepalan salah satu telapak tangan. Pijatan counter pressure dapat diberikan dalam gerakan lurus atau lingkaran kecil. Teknik ini efektif menghilangkan sakit punggung pada persalinan. (Danuatmaja, 2014).

Teknik Counter Pressure merupakan salah satu metode yang dapat mengurangi nyeri tajam dan memberikan sensasi menyenangkan dan melawan rasa tidak nyaman pada saat kontraksi atau diantara kontraksi.(Lane, 2009) 
Counter Pressure, merupakan salah satu teknik aplikasi teori gate-control, dengan menggunakan teknik pijat dapat meredakan nyeri dengan menghambat sinyal nyeri, meningkatkan aliran darah dan oksigenasi ke seluruh jaringan. Pijatan yang diberikan kepada ibu bersalin selama dua puluh menit setiap kontraksi akan lebih terbebas dari rasa sakit. Pijatan tersebut akan merangsang tubuh untuk melepaskan endorphin yang berfungsi sebagai pereda rasa sakit dan menciptakan perasaan nyaman. Pijat secara lembut membantu ibu merasa lebih segar, rileks, dan nyaman dalam persalinan. (Pillitteri, 2010)

\section{Metode Penelitian}

Cara yang digunakan dalam mencari artikel menggunakan bahasa Inggris dan Indonesia yang relevan dengan topik. Pencarian dilakukan dengan menggunakan beberapa database antara lain Google Scholar, Proquest dan Science Direct.Keyword yang digunakan adalah "Counter Pressure", "Pain/nyeri”, "labour/persalinan". Artikel yang diperoleh di review untuk memilih artikel yang sesuai dengan kriteria dan didapatkan 10 artikel yang terdiri dari 4 artikel internasional dan 6 artikel nasional yang selanjutnya akan di review.

Artikel pertama merupakan penelitian yang dilakukan oleh Sadat dkk (2016) di Rumah Sakit Amiralmomenin Iran.Metode yang digunakan adalah Eksperimen dengan jumlah responden dalam penelitian yaitu 60 orang ibu hamil. Ibu hamil dipilih secara acak kemudian dibagi menjadi dua kelompok: 30 ibu yang menerima pijatan dan 30 ibu dalam kelompok kontrol. Nyeri persalinan diukur dengan menggunakan Skala analog visual (VAS). Hasil penelitian ini menunjukkan bahwa pijatan manual secara signifikan mengurangi intensitas dan durasi nyeri persalinan di kedua tahap. Kesimpulan pada penelitian ini yaitu pemijatan manual melingkar di daerah lumbosakral (Counter Pressure) selama fase aktif persalinan dapat mengurangi nyeri persalinan secara efisien.

Artikel kedua merupakan penelitian yang dilakukan Dengsangluri dkk (2015) di India.Metode yang digunakan adalah Eksperimen dengan jumlah sampelpada penelitian ini yaitu 48 orang ibu hamilyang dibagi menjadi 2 kelompok antara lain24 orang dalam kelompok eksperimen dan 24 pada kelompok kontrol yang dibagi secara acak. Kelompok eksperimen menerima pijatan selama fase aktif persalinan sedangkan kelompok kontrol diberikan perawatan rutin. Tingkat nyeri dinilai setelah setiap kontraksi dengan skala nyeri wajah wong weber dan daftar perilaku. Hasilnya menunjukkan bahwa ada perbedaan yang signifikan antara skor nyeri rata-rata dari kelompok eksperimen dan kontrol ( $\mathrm{p}<0,001$ per t-test). Maka hipotesis nol ditolak pada tingkat signifikansi 0,05 . Jadi pijat dapat mengurangi intensitas nyeri persalinan selama tahap pertama persalinan.

Artikel ketiga merupakan penelitian yang dilakukan oleh Hosseni (2016) di Iran.Dalam penelitian deskriptif ini, 308 ibu dengan persalinan pervaginam normal dipilih secara acak dengan kriteria Inklusiyaitu usia kehamilan antara 38- 42 minggu, kehamilan tunggaldengan letak kepala, Harus ibu hamil dengan kewarganegaraan Iran, memiliki 
kehamilan berisiko rendah, tidak menggunakan obat-obatan terlarang tertentu dan non-konsumsi alkohol dan merokokselama kehamilan, plasenta dan janin normal. Ibu hamil dengan kala I persalinan diberikan terapi pijat 168 orang $(54,4 \%)$, menggunakan aromaterapi penghilang rasa sakit untuk 80 orang ( $26 \%$ ), dan metode pola pernapasan dilakukan pada 60 orang $(19,6)$. Hasil penelitian menunjukkan penggunakan pijat, aromaterapi dan pola pernapasan adalah strategi intervensi yang efektif yang dapat mengurangi rasa nyeri persalinan.

Artikel keempat merupakan penelitian yang dilakukan oleh Dabiri (2014) di Iran. Metode yang digunakan adalah pendekatan eksperimental dengan jumlah Sampel pada penelitian ini sebanyak 35 responden.Intensitas nyeri diukur dengan skala analog visual sebelum dan sesudah intervensi pada kala pertama persalinan. Tekanan atau sentuhan diberikan selama 30 menit selama kontraksi uterus.Perbedaan skor nyeri antara kelompok akupresur dan kontrol secara statistik signifikan ( $p$ $<0,001)$ tetapi tidak ada perbedaan yang signifikan secara statistik ( $\mathrm{p}=$ 0,942) dalam durasi tahap pertama persalinan antara kedua kelompok.

Artikel kelima merupakan penelitian yang dilakukan oleh Sri Rezeki dkk (2013) di di RSUD Ambarawa Kab. Semarang. Metode yang digunakan adalah Eksperimendengan jumlah sampel penelitian adalah 48 responden yang dipilih secara accidental sampling. Metode yang digunakan adalah Eksperimen dengan pendekatan one group pre test dan post test design.. Hasil penelitian menunjukkan ada perbedaan yang signifikan antara efektifitas teknik Back-Effleurage dan teknik Counter-Pressure terhadap tingkat nyeri pinggang kala I fase aktif persalinan. Dari kedua teknik tersebut Counter-Pressure lebih efektif dalam mengurangi nyeri pinggang persalinan dengan hasil nilai mean 3,63 lebih besar dibandingkan dengan teknik Back-Effleurage 2,92.

Artikel keenam merupakan penelitian yang dilakukan oleh Octa Dwienda R. Hasil penelitian, Miratu Megasari, Novita Lusiana(2015) di Pekan baru.Metode yang digunakan adalah Eksperimen denganjumlah sampel pada penelitian ini sebanyak 30 orang dengan teknik pengambilan sampel adalah Purposive Sampling. Hasil penelitian diperoleh bahwa ratarata skala nyeri persalinan sebelum pijat adalah 8,67, sesudah pijat adalah 5,33 . Sedangkan untuk metode sebelum pemberian obat anti nyeri adalah 9,47 dan sesudah pemberian obat adalah 3,07.Jadi pemberian pijat dan obat efektif dalam mengurangi nyeri dengan $p$ value : 0,001 .

Artikel ketujuh merupakan penelitian yang dilakukan oleh Satria (2018) di Klinik Bidan Elviana. Penelitian ini dilakukan dengan rancangan Quasi Eksperimendengan pendekatan pretest - posttest designJumlah Sampel pada penelitian ini sebanyak 20 orang ibu yang diambil dengan Consequtif Sampling. Hasil penelitian menunjukkan rata-rata nyeri persalinan sebelum pijatan Counter Pressureadalah 8,3 (nyeri berat) dengan skala 7-9. Rerata nyeri setelah dilakukan Counter Pressure adalah 5,1 (nyeri sedang) pada skala 37.Analisis data menunjukkan hasil yang signifikan jadi dapat diambil kesimpulan bahwa pijat Counter Pressureefektif terhadap pengurangan 
nyeri ibu ketika fase aktif kala 1 persalinan.

Artikel kedelapan merupakan penelitian yang dilakukan oleh Elin Supliyani (2016) di Bogor.Metode yang digunakan yaitu eksperimental dengan jumlah sampel pada penelitian ini sebanyak 35 orang .Penelitian ini di lakukan untuk mengetahui pengaruh pijat punggung terhadap intensitas nyeri persalinan kala 1 . Hasil penelitian ini yaitu nilai $\mathrm{p}<0.0001$ maka terdapat perbedaan rerata intensitas nyeri kala 1 persalinan sesudah dan sebelum di lakukan pijat punggung artinya adanya pengaruh pijat punggung terhadap intensitas nyeri pada persalinan kala 1 .

Artikel kesembilan merupakan penelitian yang dilakukan oleh Esti Handayani \& Pramono Giri Kiswoyo (2012) di Semarang.Metode yang digunakan adalah Eksperimen denganjumlah sampel pada penelitian ini sebanyak 35 responden pada ibu bersalin kala I fase aktif persalinan fisiologis di BPM wilayah kerja Puskesmas Tegalrejo.Pengambilan sampel dalam penelitian ini dengan menggunakan sampel jenuh atau total sampling. Hasil penelitian menunjukkan yaitu Ada pengaruh pijat punggung terhadap pengurangan nyeri kala I fase aktif persalinan pada ibu bersalin normal dengan nilai $\mathrm{Z}$ hitung sebesar -4,456 dengan uji 2 pihak maka nilai signifikansi $\mathrm{p}$ value sebesar 0,00 dimana $\mathrm{P}<\alpha 0,05$.

Artikel kesepuluh merupakan penelitian yang dilakukan oleh Seri Pasongli dkk (2014) di Rumah Sakit Advent Manado.Metode penelitian yang digunakan yaitu bersifat deskriptif analitik.dengan desain penelitian OneGroup Pretest-Postest designuntuk mengetahui efektifitas Counter
Pressure terhadap penurunan intensitas nyeri kala I fase aktif persalinan normal. Jumlah sampel 15 orang ibu inpartu kala I yang memenuhi kriteria inklusi.Teknik sampling dalam penelitian ini menggunakan Simple Random Sampling. Hasil penelitian menunjukkan bahwa teknik counter pressure lebih efektif untuk menurunkan nyeri pada persalinan normal.

\section{Hasil dan Pembahasan}

Dari hasil literature review yang telah dipaparkan tidak semua artikel menjelaskan hasil penelitian tentang Counter Pressure tetapi ada juga tentang kombinasi antara Counter pressure dengan latihan pernafasan, masase punggung, back-efflurage sehingga dapat digunakan sebagai dasar review jurnal penelitian.

Dari sepuluh jurnal yang di sajikan 8 diantaranya menggunakan metode eksperimen dan 2 menggunakan metode deskriptif analitik. Penilaian skala nyeri persalinan sebagian diukur dengan menggunakan Skala analog visual (VAS) dan skala nyeri wajah wong weber. Hasil penelitian rata-rata skala nyeri sebelum di lakukan Counter pressure berada pada skala berat namun setelah di lakukan Counterpressureskala nyeri menurun menjadi skala sedang.

Counter pressure dapat dikategorikan sebagai intervensi yang aman dan cukup efektif untuk mengurangi nyeri persalinan pada kala I.Counter Pressure dilakukan dengan memberikan tekanan pada saat kontraksi pada tulang sakrum pasien dengan pangkal atau bisa juga dengan kepalan salah satu telapak tangan(Andarmoyo, 2013) . 
Teknik counter pressure ini di lakukan di daerah lumbal dimana saraf sensorik rahim dan mulut rahim berjalan bersama saraf simpatis rahim memasuki sumsum tulang belakang melalui saraf torakal 10-11-12 sampai lumbal 1. Dengan begitu impuls rasa sakit ini dapat diblok yaitu dengan memberikan ransangan pada saraf yang berdiameter besar yang menyebabkan gate control akan tertutup dan ransangan sakit tidak dapat diteruskan ke korteks serebral (Bobak IM, 2012)

Melalui teknik Counter Pressureakan menutup rangsangan nyeri yang akan dihantar menuju medulla spinalis dan otak. Senyawa endorphin akandiaktifkan pada saat dilakukan Counter Pressure sehingga transmisi dari pesan nyeri dapat dihambat yang dapat menyebabkan penurunan sensasi nyeri. (Aprilia, 2011)

Counter pressure juga bekerjaberdasarkan teori opiate endogenous, yang mengatakan bahwa reseptor opiate yang berada pada otak dan spinal cord bekerja pada sisitem saraf pusat untuk mengaktifkan endhorphin dan enkephaline apabila nyeri timbul. Selain itu, counter pressure juga dapat merangsang pengeluaran opiate reseptor yang berada pada ujung saraf sensori perifer melalui tekanan dan pijatan. Dengan pijatan dan tekanan yang kuat dapat mengeblok dan mengaktifkan endhorphin yang dapat membuat relaksasi otot sehingga nyeri pun berkurang(Pratiwi \& Nurullita, 2017)

Teknik Counter Pressure sangat efektif untuk mengurangi nyeri punggung selama persalinan. Dengan cara ini, dapat mengurangi nyeri dan memberikan sensasi yang nyaman untuk melawan rasa sakt saat kontraksi ataupun di antara kontraksi. (Ma'rifah, 2014)

Penelitian mengenai pengaruh teknik back-efflurage dan counter pressure menyebutkan bahwa counter pressure lebih efektif mengatasi nyeri persalinan fase aktif kala I. Teknik counter pressure dapat menutup rangsangan nyeri yang akan dihantarkan menuju medulla spinalis dan otak, selain itu dengan tekanan yang kuat dapat mengaktifkan senyawa endorphin yang berada di sinaps sel-sel saraf tulang belakang dan otak, sehingga nyeri dapat dihambat dan sensasi nyeri dapat menurun. (Yuliatun, 2008)

\section{Simpulan}

Simpulan berdasarkan analisa yang telah dilakukan oleh penulis, disimpulkan bahwa penggunaan Counter Pressure efektif untuk mengurangi nyeri persalinan kala I.

Saran yang dapat diberikan untuk pelaksanaan literature review selanjutnya adalah sebaiknya database yang digunakan lebih banyak sehingga bisa mendapatkan artikel yang lebih banyak dan baik dan batasan tahun pencarian artikel dengan kata kunci yang ditetapkan adalah lima tahun terakhir agar literature lebih update.

\section{Daftar Pustaka}

Andarmoyo. (2013). Persalinan Tanpa Nyeri Berlebihan : Konsep dan Aplikasi Manajemen Nyeri Persalinan. Yogyakarta: ArRuzz Media.

Aprilia, Y. d. (2011). Birth Melahirkan Nyaman Tanpa Rasa Sakit. . Jakarta: Gramedia. 
Azizah, I. N., Widyawati, M. N., \& Anggraini, N. N. (2013). Pengaruh Endorphin Massage Terhadap Intensitas Nyeri Kala I Persalinan Normal Ibu Primipara di BPS S dan B Demak Tahun 2011. Jurnal Kebidanan, 2(1).

Bobak IM, L. D., Jensen MD, Perry SE. (2012). Buku Ajar Keperawatan Maternitas (Maternity Nursing). Jakarta: EGC.

Dabiri, F., \& Shahi, A. (2014). The effect of LI4 acupressure on labor pain intensity and duration of labor: a randomized controlled trial. Oman medical journal, 29(6), 425.

Danuatmaja, B. d. M. (2014). Persalinan Normal Tanpa Rasa Sakit. . Puspa Swara.

Dengsangluri, J. A. S. (2015). Effect of breathing exercise in reduction of pain during first stage of labour among primigravidas. Int J Health Sci Res IJHSR, 5(6), 390-398.

Detiana. (2010). Hamil Aman dan Nyaman di Atas 30 Tahun. Yogyakarta:Medika Pressindo.

Handayani, E., \& Kemenkes, P. G. K. P. K. (2012). PENGARUH MASASE PUNGGUNG TERHADAP

PENGURANGAN NYERI PERSALINAN KALA I FASE AKTIF PADA IBU BERSALIN NORMAL DI BPM WILAYAH KERJA PUSKESMAS TEGALREJO KABUPATEN MAGELANG TAHUN 2012. Jurnal Kebidanan, 4(2).

Hosseni, S. F., Pilevarzadeh, M., \& Vazirinasab, H. (2016). Non-
Pharmacological Strategies on Pain Relief During Labor. Biosciences Biotechnology Research Asia, 13(2), 701-706.

Lane. (2009). Massage In Childbirth. How To Touch Can Provide Pain Relief During Labour.

Ma'rifah, A. R. (2014). EFEKTIFITAS

TEHNIK COUNTER

PRESSURE $D A N$ ENDORPHIN

MASSAGETERHADAP NYERI PERSALINAN KALA I PADA

IBU BERSALIN DI RSUD AJIBARANG. Paper presented at the Prosiding Seminar Nasional \& Internasional.

Okta Dwienda, M. M., Novita Lusiana,. (2015). Efektifitas Pijat dalam Mengurangi Nyeri Kala I Persalinan. Volume 2 No. 6

Pasongli, S., Rantung, M., \& Pesak, E. (2014). Efektifitas Counterpressure Terhadap Penurunan Intensitas Nyeri Kala I Fase Aktif Persalinan Normal di Rumah Sakit Advent Manado. Jurnal Ilmiah Bidan, 2(2).

Pillitteri. (2010). Maternal and Child Health Nursing : Care of The Childbearing Family

Pratiwi, D., \& Nurullita, U. (2017). PERBEDAAN EFEKTIFITAS TEHNIK COUNTERPRESSUREDAN KOMPRES HANGAT TERHADAP PENURUNANNYERI PERSALINAN KALA I FASE AKTIFDI RSUD SUNAN KALIJAGA DEMAK. Karya Ilmiah S. 1 Ilmu Keperawatan.

Reeder S.J. Martin L.L, K. D. (2014). Maternity Nursing, Family, 
Newborn and Women's Health.

Lippincolt, Philadelpia.

Rejeki, S., Nurullita, U., \& Krestanti, R. (2013). Tingkat Nyeri Pinggang Kala I Persalinan melalui Teknik Back-Effluerage dan Counter-Pressure. Jurnal Keperawatan Maternitas, 1(2).

Sadat, H. Z., Forugh, F., Maryam, H., Nosratollah, M. N., \& Hosein, S. (2016). The impact of manual massage on intensity and duration of pain at first phase of labor in primigravid women. International Journal of Medicine Research, 1(4), 1618.

Satria, M. (2018). PENGARUH SEBELUM DAN SESUDAH DILAKUKAN PIJAT PUNGGUNG TEKNIK COUNTERPRESSURE TERHADAP PENGURANGAN RASA NYERI IBU BERSALIN KALA I FASE AKTIF DI KLINIK BIDAN ELVIANA TAHUN 2017. Menara Ilmu, 12(5).

Setyowati, H. (2018). Akupuntur untuk Kesehatan Wanita Berbasis Hasil Penelitian. Unimma Press Supliyani, E. (2017). Pengaruh Masase Punggung terhadap Intensitas Nyeri Persalinan Kala 1 di Kota Bogor. Jurnal Bidan, 3(1).

Yuliatun. (2008). Buku Pijat effleurage. Jakarta: EGC. 